\title{
IMPLEMENTATION AND TESTING OF A POWER MATRIX- BASED WAVE ENERGY CONVERSION MODEL AND THE EFFECT SIMULATED ON THE WAVE FIELD - CASE STUDY OF LAGUNA, SC, BRAZIL
}

\author{
P. H. Oleinik ${ }^{\mathrm{a}}$, \\ and W. C. Marques \\ ${ }^{a}$ Universidade Federal do Rio Grande \\ Escola de Engenharia \\ Av. Itália km 8 Bairro Carreiros \\ Rio Grande, Rio Grande do Sul, Brasil \\ phe.h.o1@ gmail.com \\ bUniversidade Federal do Rio Grande \\ Instituto de Matemática, Estatística e Física \\ Av. Itália km 8 Bairro Carreiros \\ Rio Grande, Rio Grande do Sul, Brasil \\ wiliam_marques@yahoo.com.br
}

Received: January 29, 2019 Revised: February 28, 2019

Accepted: April 29, 2019

\begin{abstract}
Electrical energy has become an essential resource for mankind and, as the population and technological dependency grow, also does the electricity demand. This necessity boosted numerous studies which focus on clean and renewable energy sources. Ocean wave energy is one of the most environmentally friendly sources of energy since it does not emit pollutants to the atmosphere and does not produce harmful waste. Another positive point about ocean waves is that they are inexhaustible, therefore a power plant could, potentially, provide energy indefinitely. Hence the object of this study is to estimate the wave energy reduction caused by the presence of wave energy conversion (WEC) devices near the coastline of Laguna, Brazil. In order to study the coastal impact of a WEC farm, the third generation sea state model TOMAWAC was used to simulate the waves on the Southern Brazilian Shelf under two different conditions, with and without the presence of an array of WECs. The results show that the mean significant wave height in the blockaded area undergoes a slight drop, caused by the presence of the WECs, which do not appear in the other scenario. But this reduction of the significant wave height is negligible compared to the order of magnitude of the wave height itself.
\end{abstract}

Keywords: wave energy; spectral modelling; TOMAWAC; WaVESCoM; F-2HB

\section{NOMENCLATURE}

$a_{\mathrm{m}} \quad$ Amplitude of a wave component, $\mathrm{m}$

$D_{\mathrm{m}} \quad$ Mean wave direction, ${ }^{\circ}$

$D_{\mathrm{p}} \quad$ Spectral peak wave direction, ${ }^{\circ}$

$E \quad$ Directional wave energy spectrum, $\mathrm{kg} / \mathrm{s}^{2}$

$f \quad$ Wave frequency, $\mathrm{Hz}$

$g$ Acceleration of gravity $\mathrm{m} / \mathrm{s}^{2}$

$H_{\mathrm{s}} \quad$ Significant wave height, $\mathrm{m}$

$k_{\mathrm{x}}, k_{\mathrm{y}}$ Wave number vector, $\mathrm{m}^{-1}$

$N \quad$ Wave action density spectrum, $\mathrm{m}^{2} /(\mathrm{Hz} \mathrm{rad})$

$P_{\mathrm{w}} \quad$ Wave energetic potential, $\mathrm{kW} / \mathrm{m}$

$Q \quad$ Source term of Eq. (1), $\mathrm{m}^{2} / \mathrm{rad}$

$t \quad$ Time, $\mathrm{s}$

$T_{\mathrm{p}} \quad$ Spectral peak wave period, $\mathrm{s}$

$x, y \quad$ Axes of the Cartesian coordinate system, $\mathrm{m}$

\section{Greek symbols}

$\theta \quad$ Wave direction, ${ }^{\circ}$

$\rho \quad$ Specific mass, $\mathrm{kg} / \mathrm{m}^{3}$

\section{INTRODUCTION}

Electrical energy has become an essential resource for mankind and, as the population and technological dependency both grow, also does the demand for electricity. This necessity boosted numerous researches in this field. A great deal of these studies focus on clean and renewable energy sources.

Ocean wave energy is one of the most environmentally friendly energy sources since it does not emit pollutants to the atmosphere neither produces harmful waste. Another positive point about ocean waves is that they are inexhaustible, therefore a power plant could, if correctly operated, provide energy indefinitely.

Though, a few aspects about wave energy must be considered. First there is the lack of concrete studies on wave energy harvesting feasibility, since it is a rather new technology. The great advances in computational power in the last few decades is what made most of the recent studies in this field possible.

Magagna and Uihlein (2015) compared the production cost of energy from several of the currently used sources. The most expensive ones are wave energy and tidal energy (around $€ 55 / \mathrm{kWh}$ and $€ 40 / \mathrm{kWh}$, respectively), possibly due to the harshness of the environment they are installed in. However, Magagna and Uihlein (2015) still pointed out that the expectation for the future is that these technologies will have a production cost reduction of about $85 \%$, bringing their cost near to that of more mature energy sources, such as solar, wind, and hydroelectric energy.

Wave energy research is divided primarily in two distinct branches. The first, in the engineering side of the subject, is the development and optimization of Wave Energy Conversion (WEC) devices seeking the 
maximum energy conversion ratio. The other, at the oceanographical perspective, is the sea-state simulation of the theoretical power available for conversion, as well as temporal fluctuations of this potential.

In the past few years researchers started to agree that to have a good prediction of the feasibility of a WEC farm, neither of these fields, alone, is enough. The study of the device itself usually lacks the utilization of actual sea state data to provide realistic results, and the sea state simulation does not provide information on the amount of converted energy.

This separation exists primarily because of the great difference of both approaches, and the greatest difficulty is the different time scales involved. Sea state simulations use time steps varying from around $15 \mathrm{~min}$ to $60 \mathrm{~min}$, and can last from a few days up to a few decades, while the WEC device simulations require time steps as small as $1 \mathrm{~s}$, due to the complexity of the processes involved, and usually only last a couple of hours. Thus both approaches cannot be simply put together, because it will require a larger computational power than the currently available.

In an attempt to bring these fields together to improve the understanding of the wave energy harvesting process, a few studies have already tried to either insert actual sea state data as boundary condition for wave energy conversion devices (Ferguson et al., 2017; Vyzikas et al., 2017), or have used simplified approaches to represent the WEC devices in the sea state models (Millar et al., 2007; Smith et al., 2012; Oleinik et al., 2019a).

In this paper, the second approach is considered. The devices will be inserted in a third generation sea state model to simulate the effect of the presence of an array of wave energy conversion devices on the wave field of the environment they are inserted in.

\section{MATERIAL AND METHODS}

\section{The Wave Model - ToMAWAC}

The wave model used on this study is the third generation sea state model TOMAWAC (TELEMAC-Based Operational Model Addressing Wave Action Computation), part of the Open TELEMAC-Mascaret modeling suite.

$$
\begin{aligned}
\frac{\partial N}{\partial t}+\frac{\partial(\dot{x} N)}{\partial x}+\frac{\partial(\dot{y} N)}{\partial y}+\frac{\partial\left(\dot{k}_{x} N\right)}{\partial k_{x}}+\frac{\partial\left(\dot{k}_{y} N\right)}{\partial k_{y}} \\
=Q\left(k_{x}, k_{y}, x, y, t\right)
\end{aligned}
$$

TOMAWAC solves the Eq. (1) of conservation of wave action density for the directional wave spectrum, in which $N$ is the directional wave spectrum, $x$ and $y$ are the axes of the coordinate system, $k_{x}$ and $k_{y}$ are the components in $x$ and $y$ of the wave number vector, and $t$ is the time. Equation (1) represents that, in a general situation of waves propagating in a non-homogeneous and unsteady environment, $N$ is preserved within the source terms, defined by $Q$ (Awk, 2017).

TOMAWAC solves the propagation of the winddriven waves and takes into account their gain and loss of energy by the main processes involved, such as the wind action, bottom friction-induced dissipation, shoaling, whitecapping, depth-induced refraction, and the non-linear interactions between waves.

TOMAWAC represents the sea state by splitting the directional wave spectrum into a finite number of frequencies and directions $(N(f, \theta))$, then solves Eq. (1) for each component $\left(f_{i}, \theta_{i}\right)$ of the spectrum using the finite element method.

The integration of the wave energy spectrum $(N(f, \theta))$ along the discretized frequencies and directions gives the energy per unit area of the multidirectional random wave field:

$$
\sum_{f}^{f+\mathrm{d} f} \theta+\mathrm{d} \theta \frac{1}{\theta} \rho g a_{m}^{2}=E(f, \theta) \mathrm{d} f \mathrm{~d} \theta
$$

where $\rho$ is the specific mass of the medium, $g$ is the acceleration of gravity, and $a_{m}$ is the amplitude of each wave component.

\section{The Study Area}

Figure 1 shows the computational grid used for the simulations, from Mostardas, RS on the south to Itanhaém, SP on the north. At the centre of the coastline of the domain, is the Cape of Santa Marta. The domain extends itself $700 \mathrm{~km}$ to the ocean, to the depth of $4000 \mathrm{~m}$. The distance between the mesh nodes is approximately $10000 \mathrm{~m}$ in deep ocean, reducing to $500 \mathrm{~m}$ on the coastal area, and $100 \mathrm{~m}$ at the study area.

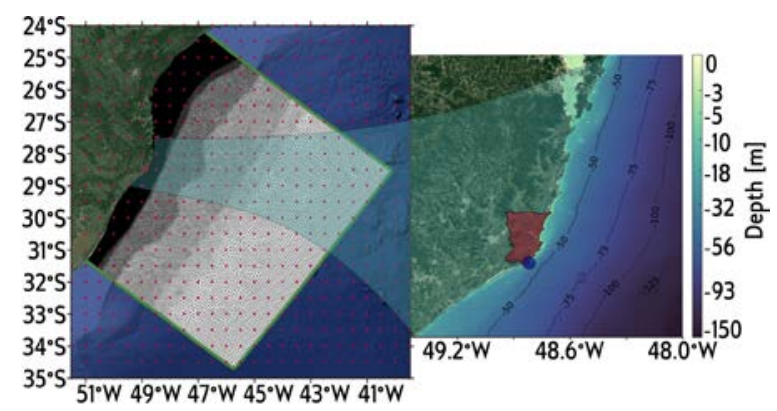

Figure 1. Computational grid along the Brazilian coastline. The green lines around the mesh in the figure to the left show where the boundary conditions were imposed and the dots show the grid of the datasets used.

The figure to the right shows a detail of the coastline with the city of Laguna highlighted, and the circle shows the Cape of Santa Marta.

The time period used for the case study is the year of 2014 because, in average, the El Niño index is nearly zero $^{1}$. Although the El Niño oscillation does not have a direct effect on the sea state, it significantly changes the wind regime (Piola et al., 2005), which is the main wave-generating force. This results in a significant 
change in the mean wave field when comparing extreme El Niño with La Niña years (Reguero et al., 2015).

The oceanic boundaries of the computational domain were forced by wave data (Significant Wave Height $-H_{\mathrm{s}}$, Peak Period $-T_{\mathrm{p}}$, and Spectral Peak Direction $-D_{\mathrm{p}}$ ) with temporal resolution of 3 hours, and wind fields with temporal resolution of 6 hours from NOAA's (National Oceanic and Atmospheric Administration) WAVEWATCH $\mathrm{III}^{2}$, with spatial resolution of $0.5^{\circ}$

The calibration and validation of TOMAWAC for this region has already been performed for earlier studies by Oleinik et al. (2017, 2019b), so this stage was skipped in this article.

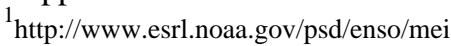

${ }^{2}$ http://polar.ncep.noaa.gov/waves/hindcasts/prod-multi_.php

\section{The Energy Conversion Module}

There are several approaches to simulate WEC devices. Some authors used absorption coefficients (Millar et al., 2007), while others used frequencydependent coefficients (Smith et al., 2012; Folley and Whittaker, 2010). For this article, though, the approach selected was with power matrices.

Power matrices are functions of two variables, namely $H_{\mathrm{s}}$ and $T_{\mathrm{p}}$, which map the amount of energy that the device can absorb from the waves. Power matrices are usually obtained by physical or numerical modelling of the devices. Babarit et al. (2012) used a numerical Wave-to-Wire model to study the performance of eight wave energy conversion devices. Their paper presents a summary and the power matrices of these devices.

Babarit et al. (2012) presented a Floating two-body heaving converter (F-2HB). Since this converter does not require to be attached to the sea floor, it can be installed at arbitrarily deep waters, as long as it's deeper than the draft of the floater plus the oscillation of the sea surface. For this reason this was the chosen device to be implemented for the present work. The power matrix of the F-2HB was implemented into the wave energy conversion module WaVESCOM.

Table 1. Power matrix of the F-2HB (Babarit et al., 2012). The top row is $T_{\mathrm{p}}$, and the left column is $H_{\mathrm{s}}$. Each pair $\left(H_{\mathrm{s}}, T_{\mathrm{p}}\right)$ maps to one value of converted power.

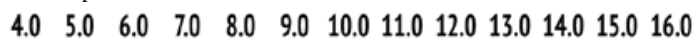
7.0 NaN NaN NaN 78110001000100010001000959748574472 6.5 NaN NaN NaN 7881000100010009791000727577435424 6.0 NaN NaN NaN $7119529741000838 \quad 886 \quad 648501 \quad 503 \quad 396$ $\begin{array}{lllllllllll}5.5 & \text { NaN NaN NaN } 610 & 774 & 880 & 936 & 905 & 805 & 603 & 456 & 397 & 311\end{array}$

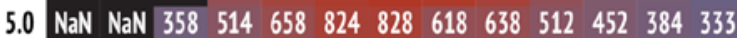

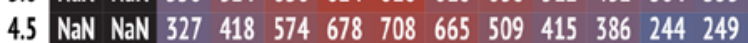

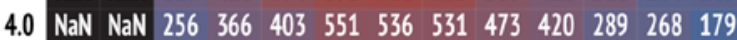
$\begin{array}{llllllllllll}3.5 & \text { NaN NaN } 192 & 254 & 291 & 431 & 385 & 424 & 314 & 285 & 239 & 222 & 172\end{array}$ $\begin{array}{llllllllllllll}3.0 & \text { NaN } & 96 & 137 & 205 & 244 & 358 & 293 & 353 & 260 & 248 & 184 & 137 & 120\end{array}$ $\begin{array}{llllllllllllll}2.5 & \text { NaN } & 65 & 104 & 141 & 191 & 179 & 243 & 255 & 190 & 181 & 135 & 99 & 83\end{array}$ $\begin{array}{lllllllllllllll}2.0 & 24 & 45 & 65 & 100 & 121 & 153 & 175 & 151 & 122 & 126 & 87 & 61 & 58\end{array}$ $\begin{array}{lllllllllllllll}1.5 & 13 & 25 & 43 & 55 & 68 & 90 & 102 & 92 & 91 & 66 & 65 & 45 & 37\end{array}$ $\begin{array}{llllllllllllll}1.0 & 6 & 11 & 19 & 25 & 30 & 44 & 50 & 53 & 44 & 34 & 22 & 20 & 17\end{array}$ $\begin{array}{lllllllllllllll}0.5 & 2 & 3 & 5 & 6 & 8 & 13 & 14 & 12 & 10 & 9 & 6 & 5 & 4\end{array}$
WaVESCoM (Wave Variance Spectrum Energy Conversion Module) takes as input the coordinates of the WEC devices and the power matrix to be used in an external file, formatted as in Tab. 1. WaVESCoM takes the variance spectrum from TOMAWAC, then computes $H_{\mathrm{s}}$ and finds the discretized spectral peak period $\left(T_{\mathrm{p}}\right)$.

With the pair $\left(H_{\mathrm{s}}, T_{\mathrm{p}}\right)$ WaVESCOM calls a bilinear interpolation procedure to get the value from the matrix. If the pair $\left(H_{\mathrm{s}}, T_{\mathrm{p}}\right)$ points to a value outside the matrix or to the region with $\mathrm{NaN}$, the converted power is zero, because presumably the device isn't designed to work under those sea state conditions.

With this interpolation WaVESCoM obtains the amount of wave energy converted by the device, and then returns the wave spectrum back to TOMAWAC after the energy loss. This energy loss is the ratio between the energetic potential $\left(P_{\mathrm{w}}\right)$ and the power converted divided by de device width. The variance spectrum is reduced by this ratio and then returned to TOMAWAC to be propagated in the next iteration of the wave model.

\section{The Wave Farm}

The spatial arrangement has a fundamental role in the collective efficiency of the devices, because when a wave passes through an obstacle, it loses energy, so when it reaches the next device, the available energy for conversion is lower. This effect can accumulate along the WEC array, and can cause a significant reduction in the expected efficiency of the converters.

Several authors have already studied the device arrangement problem (Ruiz et al., 2017; Noad and Porter 2015). This type of study is a big challenge because each device in the array influences every other and, reciprocally, every device is subject to the influence of the others, thus the complexity of the interactions increase with the number of devices.

Bozzi et al. (2017) simulated the behaviour of four devices by changing their relative position, the distance between them, and the wave action direction. These authors sought to optimize the q-factor, which is the ratio between the power obtained from the four devices operating together, and the power obtained by each device operating alone.

The results obtained by Bozzi et al. (2017) showed that the q-factor depends on the wave action direction except in the specific situation where the devices are arranged in a rhombus shape and the space between them is 10 times their diameter. In such case the q-factor is 1.05 and does not depend on the wave direction.

Since variable conditions are used in the present study this configuration which does not depend on the wave direction is the most favourable in terms of efficiency of the WEC array. Although it's worth emphasizing that the conditions used by Bozzi et al. (2017) are constant, and the results are for four devices only, so the real efficiency may vary.

The converters were arranged with an approximate distance of 10 times their diameter in a rhombus shape. This layout was replicated in the longitudinal and 
transversal directions relative to the overall orientation of the coast line, as showed in Fig. 2. The array was oriented taking advantage of the fact that waves usually propagate orthogonally to the coastline, thus reducing possible losses due to shadowing effects. The longitudinal axis of the array was positioned above the $100 \mathrm{~m}$ isobath.

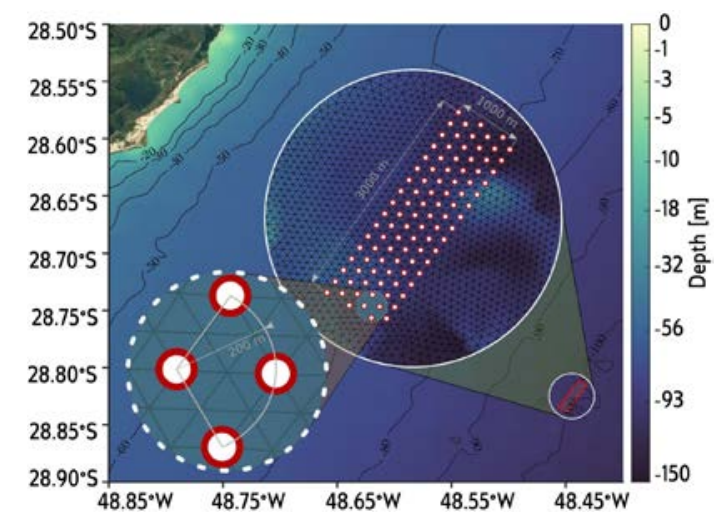

Figure 2. Bathymetry of the coastal of the Cape of Santa Marta and spatial disposition of the WECs.

The wave energy conversion farm simulated was composed of 99 WECs distributed on a $3000 \times 1000 \mathrm{~m}$ area, resulting in an arrangement where the distance between one WEC and another is $200 \mathrm{~m}$ (Fig. 2), which is 10 times the diameter of the F-2HB.

The size of the wave farm is experimental. There are none, as far as the authors know, production scale wave farms operational in the world, since most existing wave farms are prototypes of one or only a few devices. Therefore, the extent of the wave farm, its location relative to the coastline, as well as the location of the WECs relative to each other was experimental. The number of devices used, on the other hand, was chosen due to a technical limitation of TOMAWAC which, by default, can take up to 99 source points. This number can be enlarged by modifying the array sizes in TOMAWAC's code, but the authors preferred to use this value as a limit to the WEC farm.

\section{RESULTS AND DISCUSSION}

Two simulations were executed to provide the results for the present paper. The computational setup for both of them was exactly the same except for the fact that in one of them, the presence of the WEC devices was taken into account.

\section{Global Results}

Firstly, since the results of both simulations in the offshore portion of the computational domain are identical, only the global results of the natural case (the scenario without the WECs) will be presented.

Figure 3 shows the time averaged $H_{\mathrm{s}}$ calculated for the whole simulated period on the computational domain, ranging from $0.5 \mathrm{~m}$ in the Santos' Basin to 2.75 $\mathrm{m}$ on deep waters. Figure 3 points towards the same conclusion presented by Oleinik et al. (2017), that the Cape of Santa Marta has the highest mean $H_{\mathrm{s}}$ closest to the shoreline when compared to neighbouring regions.

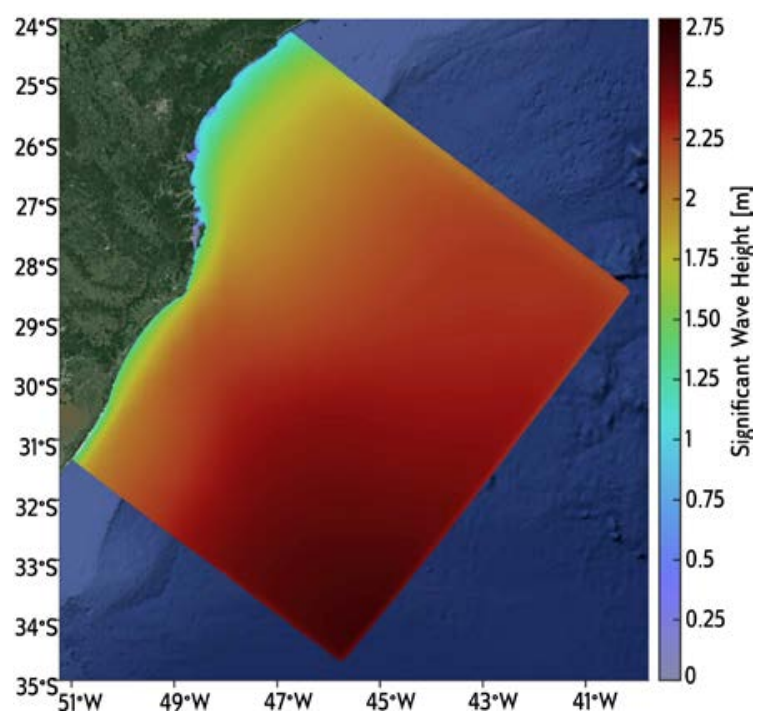

Figure 3. Time averaged surface of $H_{\mathrm{s}}$ over the computational domain, in the year of 2014. The colour maps represent the value of $H_{\mathrm{s}}$, in metres.

Figure 4 shows the time averaged $T_{\mathrm{p}}$ in the domain, with values ranging from $8.85 \mathrm{~s}$ in the South, and slightly increasing towards north east, up to $9.35 \mathrm{~s}$. It is noticeable the difference between $H_{\mathrm{s}}$ and $T_{\mathrm{p}}$, the former with higher values in the southernmost end of the domain, and the latter with higher values on the other side.

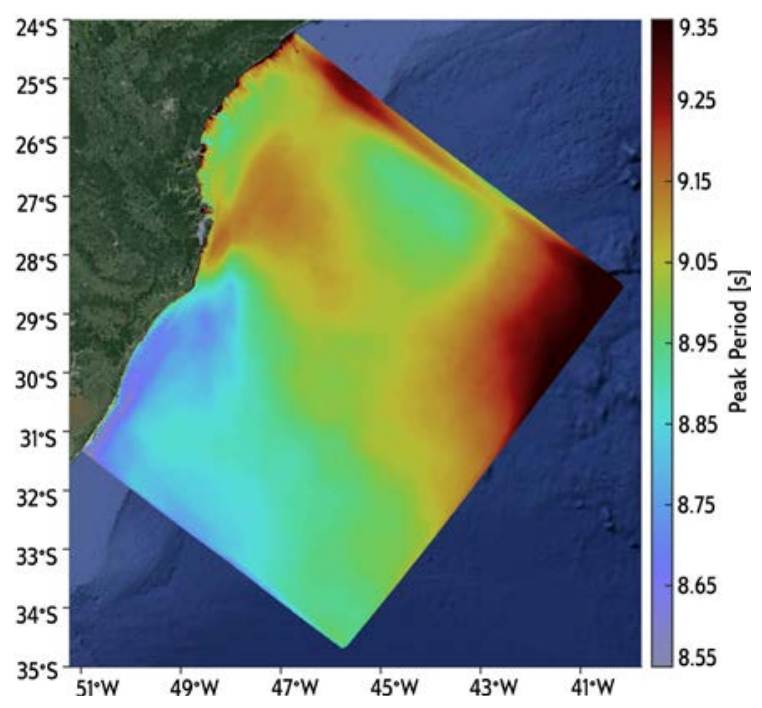

Figure 4. Same as Fig. 3, for $T_{\mathrm{p}}$, in seconds.

Figure 5 shows the mean direction $\left(D_{\mathrm{m}}\right)$ of the waves $\left(0^{\circ}\right.$ are waves traveling north and positive values are in the clockwise direction), and the circle sector provides a visual representation of this direction. Figure 5 shows that the waves travel southwest in the 
ocean and deflect towards the coastline as they approach it, and near the coastline they are, in general, perpendicular to it, due to the refraction.

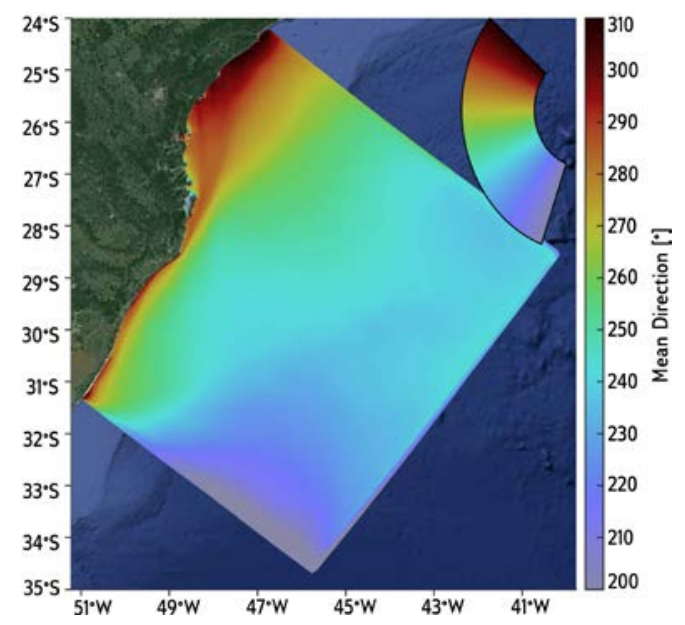

Figure 5. Same as Fig. 3, for $D_{\mathrm{m}}$, in degrees. The circle sector shows the wave propagation direction.

Figure 6 shows the mean $P_{\mathrm{w}}$ in the domain, with the smallest values in the Santos' Basin (around $5 \mathrm{~kW} / \mathrm{m}$ ), and the largest ones close to the coastline, at the Cape of Santa Marta, of approximately $15 \mathrm{~kW} / \mathrm{m}$. It is worth noting the contrast of the two mentioned regions; the increase of $P_{\mathrm{w}}$ towards the ocean is much larger at the southern portion of the mesh than in Santos' Basin. This is possibly due to the higher wind speeds that occur near the tropic.

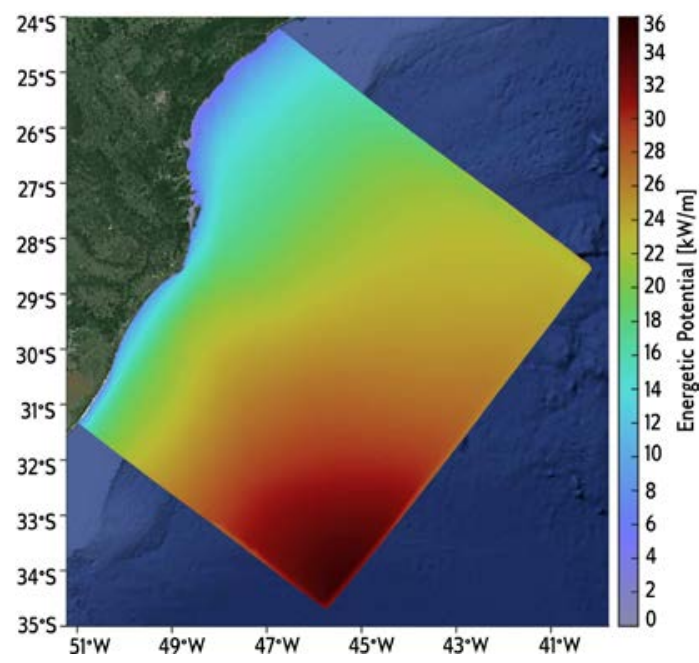

Figure 6. Same as Fig. 3, for $P_{\mathrm{w}}$, in $\mathrm{kW} / \mathrm{m}$.

\section{Scenario Comparison}

The effect of the wave farm will be analysed by means of the time averaged surfaces of the main wave parameters on the study area, and by means of the average difference of the two simulations.

The results of the modified scenario show a slight disturbance in the wave height field (Fig. 7), not enough to cause a significant reduction in the wave height and also not enough to allow concluding that such reduction actually happens. Considering that the empty space between the devices is 10 times their diameter and, more importantly, that the wave lengths usually range from a few tens to a few hundred metres, much larger than the width of the F-2HB, so its presence should be barely noticeable to the waves.

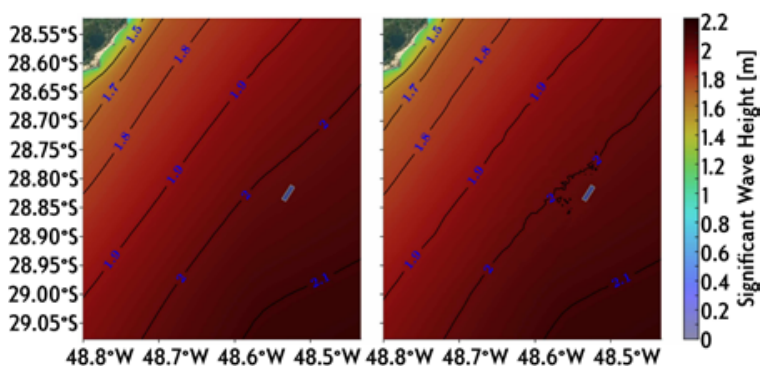

Figure 7. Comparison of the time averaged $H_{\mathrm{s}}$ field for the natural (left) and the modified (right) scenarios.

The difference is also negligible for the other wave parameters so their individual results will be omitted and only the average difference will be presented.

\section{Scenario Difference}

To better visualize the difference caused by the wave farm, the average of the difference was computed by subtracting the natural from the modified scenario at each time step, then computing the average.

Firstly, Fig. 8 shows the mean difference of $H_{\mathrm{s}}$ between the scenarios, showing a maximum of $3.5 \mathrm{~cm}$ of wave height loss at the southwestern side of the wave farm. The maximum difference occurs at southwest because the mean direction of the waves is south west in this location (Fig. 5), thus the WEC devices on that side will be in a "shadow" region of the other devices.

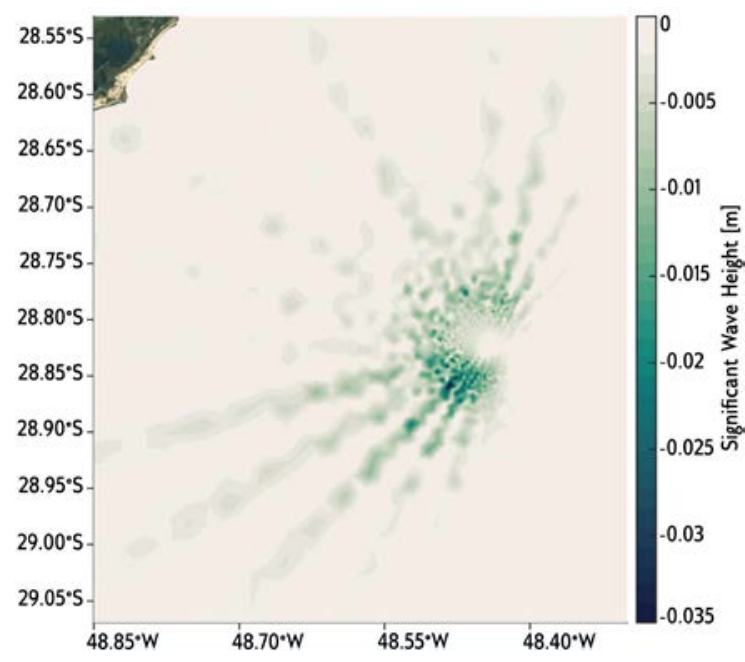

Figure 8. Time averaged difference of $H_{\mathrm{s}}$ in the study area. A negative difference means that in the modified scenario there is a loss compared to the natural scenario. 
One of the perceivable effects of the mean direction is the far-field effect of the converters which extends itself mostly westward.

Figure 8 makes clear the effect of the wave farm on the sea state of the region. There is an immediate reduction of $H_{\mathrm{s}}$ in the vicinities of the wave farm, and this difference reduces as the waves propagate, restoring their energy and dissipating the effect of the converters. It is noteworthy that the "rays" branching from the wave farm are what Booij and Holthuijsen (1987) refer to as "Garden Sprinkler effect", due to the directional discretization of the wave model. For this study TOMAWAC was discretized with 24 directions.

Figure 9 shows that there is an increase in the peak period of the waves, of almost $0.1 \mathrm{~s}$ to south west of the wave farm, and to North West, a reduction of up to $0.05 \mathrm{~s}$. This difference is possibly related to the different ondulatory regimes that exist in this region throughout the year. Further investigation is necessary to understand the reason for this difference, but it possibly originates from the energy transfer between wave frequencies indirectly caused by the presence of the devices. One should also note that $T_{\mathrm{p}}$ is a discrete variable, thus the small difference can be caused by few border cases in which a slight change of the spectral shape caused the $T_{\mathrm{p}}$ to step from one frequency to another, causing a larger difference than it should.

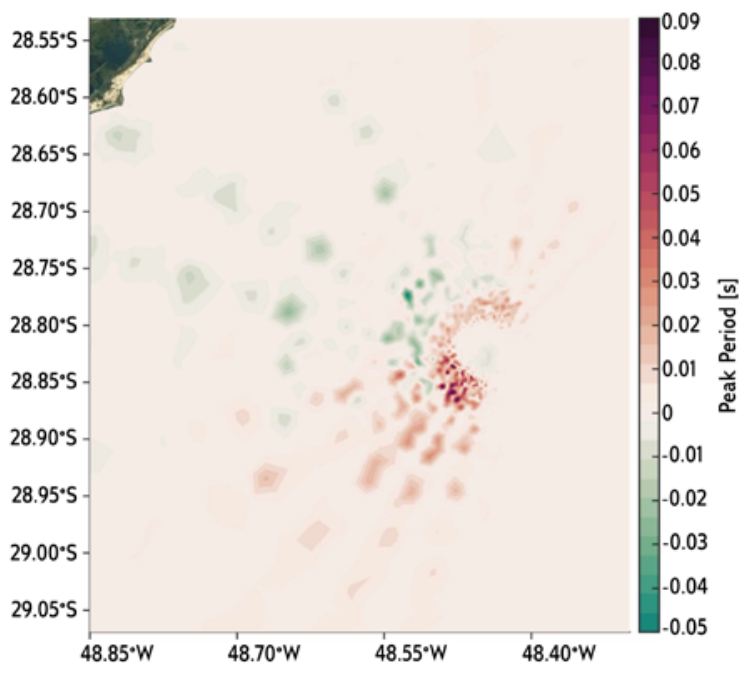

Figure 9. Same as Fig. 8, for $T_{\mathrm{p}}$.

Figure 10 shows the mean difference of $D_{\mathrm{m}}$ on the simulated year. This figure shows the numeric value of the deflection caused by the presence of the WEC devices. Since the direction convention is positive in the clockwise direction, positive differences mean a deflection in the clockwise direction caused by the presence of the wave farm. Thus Fig. 10 shows that when entering the wave farm the waves are deflected clockwise, and when leaving it they suffer a counter clockwise deflection. This shows that the effect of the WEC devices on the wave direction is similar to a refraction effect caused by a sandbank on the sea bottom.

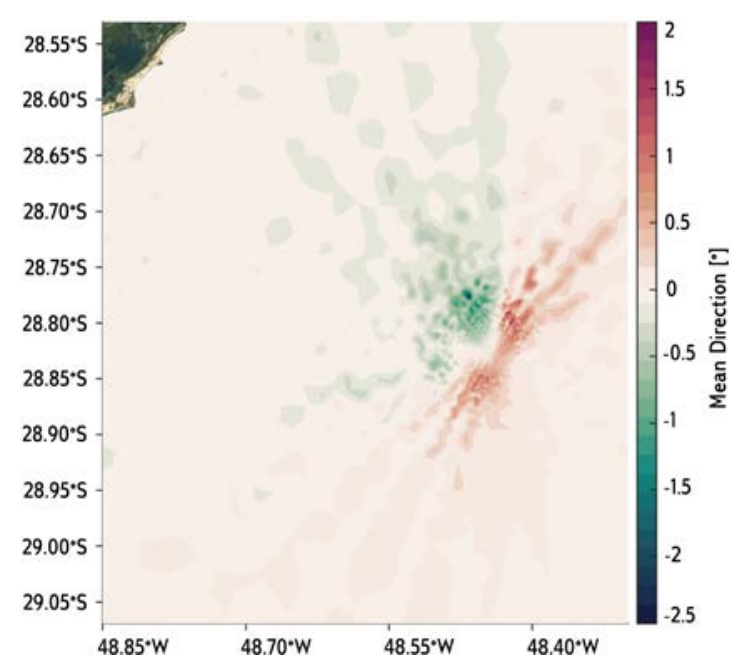

Figure 10. Same as Fig. 8, for $D_{\mathrm{m}}$.

Finally, from Fig. 11 it is possible to see the decrease of the wave energy potential due to the converters. This figure shows a result very similar to that of $H_{\mathrm{s}}$ (Fig. 8), showing the greatest difference, of $0.6 \mathrm{~kW} / \mathrm{m}$, on the south-western side of the farm.

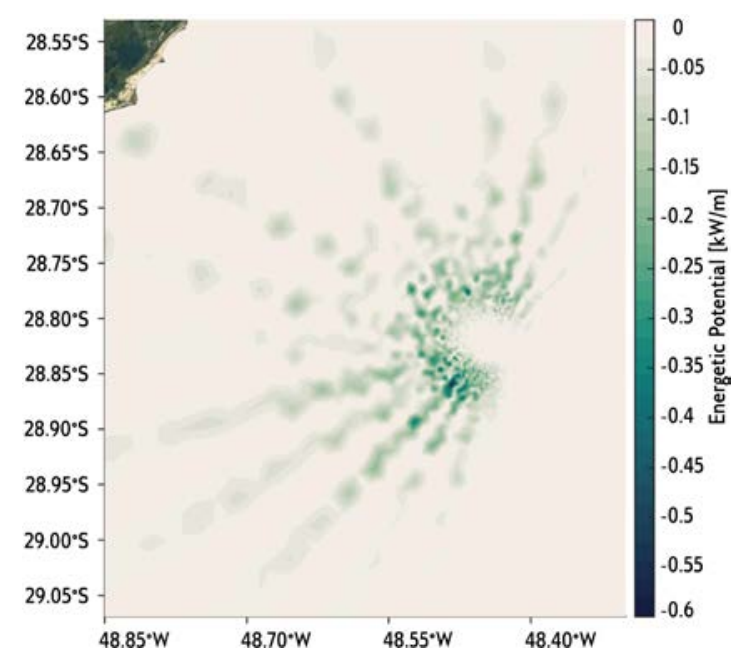

Figure 11. Same as Fig. 8, for $P_{\mathrm{w}}$.

\section{CONCLUSIONS}

This paper featured the utilization of a novel wave energy conversion model that can be coupled with a spectral wave model to estimate the impact caused by a wave farm in the environment it is inserted in.

The installation of this wave farm near the coastline of Laguna - SC didn't show itself as a threat to the environment because, even though the wave heights have suffered a small reduction (maximum of $1.8 \%$ ), it was not a significant value that could bring any harm to the local hydrodynamics. Although this conclusion is being drawn solely from the analysis of the wave field which, by itself, is not enough to provide concrete proof that the wave farm would or not cause future problems.

From the perspective of the wind waves, the action of the WEC devices does not change deeply the 
environment. The mean $H_{\mathrm{s}}$ reduction was $0.035 \mathrm{~m}$, associated with an increase in $0.9 \mathrm{~s}$ in the mean $T_{\mathrm{p}}$ and a maximum deflection of the wave direction of $2.5^{\circ}$, in average. These values are much smaller than the changes caused by other environmental factors.

Also, these small changes in the wave field are justified by the possible benefit of the installation of the wave farm, which could reduce the cost of the energy for the cities it would supply.

In order to provide a solid argument in favour or against the installation of a wave farm, further studies should be performed considering different aspects of the project. One of them should be the utilization of different types of WEC devices and their arrangement in order to create the most economically viable configuration of the wave farm. Another indispensable study should be the hydrodynamic analysis of the region coupled with a morphodynamic study to determine if the presence of the wave farm would not trigger erosive processes or any other drastic changes in the region.

The wave energy conversion model has yet to be thoroughly improved to be confidently used for wave energy budget and impact assessment. One important aspect that has to be taken into account is the nonlinear effects caused by the devices on the waves and on other devices. Phase-dependent effects, which are not currently taken into account by TOMAWAC should also be included in the modelling setup.

Once the subject is thoroughly studied, arguments could be provided to support the installation of a wave farm on this location or provide a background for the installation on other places.

\section{ACKNOWLEDGEMENTS}

The authors are grateful to the Centro de Hidrografia da Marinha of the Brazilian Navy for the bathymetric data; to NOAA for the wind and wave data; and to the Open TELEMAC-Mascaret consortium for the continuous development of the modeling suite. This research was developed using the resources of the Centro Nacional de Supercomputação, and the Laboratório Nacional de Computação Científica. This study was financed in part by the Coordenação de Aperfeiçoamento de Pessoal de Nível Superior - Brasil (CAPES) - Finance Code 001.

\section{REFERENCES}

Awk, T., 2017, Tomawac User Manual Version 7.2.3, The TELEMAC-Mascaret Consortium.

Babarit, A., Hals, J., Muliawan, M., Kurniawan, A., Moan, T., and Krokstad, J., 2012, Numerical Benchmarking Study of a Selection of Wave Energy Converters, Renewable Energy, Vol. 41, pp. 44-63.

Booij, N., and Holthuijsen, L. H., 1987, Propagation of Ocean Waves in Discrete Spectral Wave Models, Journal of Computational Physics, Vol. 68, No. 2, pp. 307-326.

Bozzi, S., Giassi, M., Moreno Miquel, A., Antonini, A., Bizzozero, F., Gruosso, G., Archetti, R., and Passoni, G., 2017, Wave Energy Farm Design in Real Wave Climates: the Italian Offshore, Energy, Vol. 122, pp. 378-389.

Ferguson, T. M., Penesis, I., Macfarlane, G., and Fleming, A., 2017, A PIV Investigation of OWC Operation in Regular, Polychromatic and Irregular Waves, Renewable Energy, Vol. 103, pp. 143-155.

Folley, M., and Whittaker, T., 2010, Spectral Modelling of Wave Energy Converters, Coastal Engineering, Vol. 57, No. 10, pp. 892-897.

Magagna, D., and Uihlein, A., 2015, Ocean Energy Development in Europe: Current Status and Future Perspectives, International Journal of Marine Energy, Vol. 11, pp. 84-104.

Millar, D. L., Smith, H. C., and Reeve, D., 2007, Modelling Analysis of the Sensitivity of Shoreline Change to a Wave Farm, Ocean Engineering, Vol. 34, No. 5-6, pp. 884-901.

Noad, I., and Porter, R., 2015, Optimisation of Arrays of Flap-Type Oscillating Wave Surge Converters, Applied Ocean Research, Vol. 50, pp. 237253.

Oleinik, P. H., Marques, W. C., and Kirinus, E. d. P., 2017, Estimate of the Wave Climate on the Most Energetic Locations of the South-Southeastern Brazilian Shelf, Defect and Diffusion Forum, Vol. 370, pp. 130-140.

Oleinik, P. H., Trombetta, T. B., Guimarães, R. C., Kirinus, E. d. P., and Marques, W. C., 2019a, Comparative Study of the Influence of a Wave Energy Converter Site on the Wave Field of Laguna, SC, Brazil, Sustainable Energy Technologies and Assessments, Vol. 31, pp. 262-272.

Oleinik, P. H., Kirinus, E. d. P., Fragassa, C., Marques, W. C., and Costi, J., 2019b, Energetic Potential Assessment of Wind-Driven Waves on the South-Southeastern Brazilian Shelf, Journal of Marine Science and Engineering, Vol. 7, No. 2, pp. 2-22.

Piola, A. R., Matano, R. P., Palma, E. D., Möller Jr., O. O., and Campos, E. J. D., 2005, The Influence of the Plata River Discharge on the Western South Atlantic Shelf, Geophysical Research Letters, Vol. 32, pp. 1-4

Reguero, B. G., Losada, I. J., and Méndez, F. J., 2015, A Global Wave Power Resource and its Seasonal, Interannual and Long-Term Variability, Applied Energy, Vol. 148, pp. 366-380.

Ruiz, P., Nava, V., Topper, M., Minguela, P., Ferri, F., and Kofoed, J., 2017, Layout Optimisation of Wave Energy Converter Arrays, Energies, Vol. 10, No. 9, pp. 1262.

Smith, H. C., Pearce, C., and Millar, D. L., 2012, Further Analysis of Change in Nearshore Wave Climate Due to an Offshore Wave Farm: an Enhanced Case Study for the Wave Hub Site, Renewable Energy, Vol. 40, No. 1, pp. 51-64.

Vyzikas, T., Deshoulières, S., Barton, M., Giroux, O., Greaves, D., and Simmonds, D., 2017, Experimental Investigation of Different Geometries of Fixed Oscillating Water Column Devices, Renewable Energy, Vol. 104, pp. 248-258. 